\title{
Sinopsis del acuerdo de asociación económica entre México y Japón
}

DOI: $10.32870 /$ mycp.v7i23.239

Taku Okabe*

I ntroducción

Mientras muchos países han llevado a cabo varios tratados de comercio y asociaciones económicas en la globalización económica, hasta 1999 Japón había seguido una política de comercio exterior multilateral participando únicamente en los acuerdos de organismos como la omc (Organización Mundial del Comercio) y el APEC (Mecanismo de Cooperación de Asia Pacífico). Así, dicho país se había quedado fuera de la tendencia de globalización e integración regional. ${ }^{1}$

Sin embargo, en el año indicado, Japón dio un viraje en su política exterior y comenzó a proponer tratados bilaterales de libre comercio, y concertó un tratado de esta naturaleza por primera vez con Singapur. ${ }^{2}$

En esta tendencia, Japón en 2001 buscó la posibilidad de firmar un tratado de libre comercio con México. En el mismo sentido, México deseaba estrechar la relación económica con Asia, especialmente con Japón. Cuando el presidente mexicano de entonces, Ernesto Zedillo, visitó Japón en noviembre de 1998, propuso que se concretaran medidas para fortalecer la relación económica entre ambos países. Así, México había mandado una señal positiva para el tratado de libre comercio con Japón. El análisis sucesivo de dicha posibilidad comenzó, también, para que Japón respondiera a la propuesta por parte de México.

Este artículo enfoca el Acuerdo de Asociación Económica (AAE) recién firmado, el primero de Japón con un país latinoamericano y el primero de México con un país asiático.

* Doctor en derecho de la Universidad de Seio, Tokio, Japón. ORCID http://orcid.org/0000-0002-6645-4043
Analiza el desarrollo histórico del proceso de la concertación y sus perspectivas, y presenta el contenido y la sinopsis en general de dicho tratado.

\section{Antecedentes del proceso del AAE}

\section{Relación histórica}

México y Japón tienen una larga historia en su relación, la cual tradicionalmente ha sido amistosa. ${ }^{3}$ Los contactos entre dichos países se remontan al año 1609, cuando un gobernador general mexicano, Rodrigo de Vivero, llegó a la costa de Onjuku (actualmente se ubica en la provincia Chiba) y tuvo una audiencia con el gobernador japonés de entonces, Ieyasu Tokugawa. Unos años después, Tsunenaga Hasekura y sus partidos viajaron a México en camino de ir a una audiencia con el Papa en Roma.

Años más tarde, Japón tomó la política de aislamiento del país (año 1633). Mientras que otros países vivían la Revolución Francesa y la independencia de Estados Unidos, además de la independencia de los países de América Latina, Japón seguía con su aislamiento total (su objetivo principal era impedir la invasión de la religión católica), ya que para Japón no significaban nada estos movimientos.

En 1853 llegó un americano llamado Perry a Japón y obligó a abrir el país, y en 1858 Japón firmó un tratado con Estados Unidos sobre la amistad y el comercio. Poco después se firmaron tratados comerciales también con Rusia, Holanda, Inglaterra y Francia; pero estos tratados negaban los derechos aduaneros por parte de Japón y concedieron la extraterritorialidad a los residentes extranjeros, por 
lo tanto eran tratados desiguales, de manera humillante. ${ }^{4}$

En 1888, después de volver a abrir el país, Japón firmó el Tratado de Amistad, Comercio y Navegación con México, el cual fue el primero en términos de igualdad con un país occidental. Por dicho tratado, se hizo más íntima la relación entre México y Japón, y en 1897, los 35 japoneses de un partido colonial, que fue promovido por el señor Enomoto, empezaron a residir en Chiapas, lo cual fue la primera organización emigrante a América Latina desde Japón.

Durante las dos guerras mundiales, al no haber tenido un choque directo entre dichos países había seguido el intercambio entre ambos países positivamente. Entre México y Japón no hay problemas políticos serios o experiencias amargas en el pasado; hasta la fecha su relación ha sido básicamente amistosa.

Japón, después de la segunda guerra mundial, logró un inmenso desarrollo económico. En esta tendencia, las administraciones de Luis Echeverría y José López Portillo en la década de los setenta captaron a Japón no como un simple proveedor de capitales y tecnología alternativo a Estados Unidos, sino como una de las potencias económicas emergentes más importantes que podrían coadyuvar al desarrollo nacional. ${ }^{5}$

Recientemente, se han mantenido varias comunicaciones o cooperaciones en materia cultural y económica entre ambos países. ${ }^{6} \mathrm{Se}$ han hecho varias visitas de los ministros importantes entre México y Japón desde la década de los noventa a la fecha.

Como ya se mencionó, Japón había pugnado por abolir los tratados desiguales de entonces con los países poderosos de Europa y Estados Unidos de América. México fue el primer país que firmó el tratado de amistad "igual recíprocamente", e inspirado por dicha concertación Japón comenzó a revisar positivamente los tratados desiguales con otros países y logró firmarlos en términos de igualdad en los siguientes nueve meses. Este hecho histórico es importante resaltarlo porque Japón intentó escoger a México como su socio en un tratado de libre comercio.

\section{Inicio de las negociaciones}

En junio de 2001, el presidente Vicente Fox, al visitar Japón, se propuso analizar la conveniencia de negociar un tratado de libre comercio entre ambos países. Así, México, el mismo año, creó un equipo de estudio (Grupo de estudio México-Japón sobre el fortalecimiento de las relaciones económicas bilaterales) formado por los sectores gubernamental, privado y académico de ambas naciones, con el fin de reforzar la relación económica bilateral, incluida la posibilidad de negociar un tratado de libre comercio.

Dicho equipo de estudio se reunió en siete ocasiones y en julio de 2002 finalizó el informe ${ }^{7}$ que contiene las discusiones y recomendaciones sobre temas de comercio de bienes, comercio de servicios e inversión, reglas de comercio y posibles áreas de cooperación económica y técnica. Este informe propuso iniciar a la brevedad los trabajos para concluir un acuerdo de asociación económica como una manera concreta de fortalecer las relaciones económicas bilaterales entre México y Japón.

Con anterioridad a dicho análisis del Grupo de estudio de México, en Japón se había realizado otro estudio - sobre la posibilidad del AAE- que finalizó en abril de 2000, desarrollado por la Comisión para estrechar las relaciones económicas entre México y Japón en JETRO, con la participación de varios expertos y profesores (Report on closer economic relations between Japan and Mexico). ${ }^{8}$

Según dicho estudio, el movimiento corriente de Japón hasta ese entonces para promover el tratado de libre comercio tanto bilateral como regional señalaría al mundo un cambio de la perspectiva anterior: la política de negociación sólo multilateralmente. Si Japón se esforzara a formar el tratado de libre 
comercio con México, el riesgo del mundo (que está dividido en los tres mayores bloques constituidos de Asia, América y Europa) podría ser anticipado. Aparte de dicha vista, Japón podría consolidar una buena relación con México mediante los procesos de negociación para el tratado de libre comercio.

\section{Las rondas y la firma}

En las negociaciones del AAE entre México y Japón, se habían llevado a cabo las catorce rondas de manera alternada en ambos países. La primera fue del 18 al 19 de noviembre de 2002, en Tokio: se acordaron los elementos, alcance y calendario de la negociación. La última ronda se celebró también en Tokio, del 25 de febrero al 5 de marzo de 2004. Hasta la decimocuarta ronda ya había pactado la parte sustantiva al respecto, incluyendo los capítulos agrícola e industrial, en términos mutuamente satisfactorios y balanceados que se ajustan a los intereses de los productores y exportadores de ambos países.

En las primeras diez rondas se había avanzado de forma considerable en la mayoría de los textos de los capítulos del AAE, como los servicios e inversión, así como la cooperación bilateral de varios aspectos como la educación, la capacitación, la ciencia, la tecnología, el turismo, el medio ambiente, la pesca y la agricultura.

En la última ronda se discutieron a nivel técnico para enriquecer la definición de los textos y las disciplinas en materia de comercio de bienes: reglas de origen y procedimientos aduaneros, salvaguardias, servicios, inversión y solución de controversias. También se habían analizado aspectos específicos relativos a la cooperación bilateral orientada a fortalecer las relaciones económicas en el marco de este acuerdo.

Uno de los problemas o la diferencia que prevalecía entre México y Japón en estas negociaciones era del sector agropecuario. Tuvieron la perspectiva de concertar el acuerdo anteriormente; sin embargo, dicho asunto había sido un pendiente para ambos países.
$\mathrm{Al}$ respecto, en las rondas posteriores el equipo negociador mexicano continuó trabajando de manera intensa y constructiva a fin de asegurar que los intereses en materia de exportación de México fueran atendidos. Mientras, la parte japonesa mejoró en forma significativa su oferta de acceso al mercado de productos agroalimentarios, y en la decimotercera ronda dicho asunto registró un avance muy importante. (Las cifras al respecto se pueden ver más adelante.)

Del 25 de febrero al 5 de marzo se llevó a cabo en Tokio la decimocuarta ronda de negociaciones, donde se analizaron los temas de comercio de bienes, inversión, servicios, compras gubernamentales, solución de controversias y cooperación bilateral. En esa ocasión se terminaron todas las negociaciones oficiales.

En materia tanto de acceso a mercados de bienes como otros asuntos no resueltos, ambos países acordaron continuar realizando su mejor esfuerzo para concluir un acuerdo mutuamente satisfactorio que atendiera los respectivos intereses exportadores.

El 17 de septiembre de 2004, el presidente de México, Vicente Fox, y el primer ministro de Japón, Junichiro Koizumi, firmaron el AAE en una ceremonia en el salón de la Tesorería de Palacio Nacional, en la ciudad de México.

En las negociaciones y en el acuerdo final no se han llenado todos los deseos de ambas partes. Sin embargo, como dijo Alina Aldape, representante del sector privado mexicano: "Ni los japoneses ni nosotros obtuvimos todo lo que solicitamos, pero eso es parte de cualquier negociación, porque de otra manera no se trataría de una negociación, sino de una imposición". ${ }^{9}$ Así, se puede afirmar que las negociaciones al respecto han terminado con éxito.

El AAE entrará en vigor en abril de 2005. Como afirmó el primer ministro de Japón, Junichiro Koizumi, este tratado entre México y Japón abrirá una nueva página en las relaciones bilaterales. ${ }^{10}$ 


\section{Características económicas de a mbos países}

Uno de los motivos de concertar el AAE entre México y Japón es para complementar las ventajas y desventajas que llevan ambos países entre sí. A continuación, se citarán las características de ambas economías según los datos que se publicaron en la Secretaría de Economía de México. ${ }^{11}$

Acerca de los puntos que se han mencionado anteriormente, el AAE permitiría aprovechar la complementariedad entre las economías de México y Japón, al intensificarse las actividades bilaterales de comercio, inversión y cooperación económica.

Como muestra el cuadro, Japón es un país desarrollado, y un ejemplo más reciente de la relación con México han sido las actividades económicas de las industrias maquiladoras en la frontera norte de dicho país.
Sin embargo, ha surgido un severo problema en el comercio con México desde el punto de vista de Japón: la elevada tarifa de aquel país. La tarifa promedio era $13.2 \%$ hasta finales de 1998. En enero de 1999, México subió la tarifa para importaciones generales aplicada a los países no participantes del tratado de libre comercio, por 3 ó $10 \%$ en aproximadamente 10000 artículos, o el $85 \%$ de todas las clasificaciones de tarifas. ${ }^{12}$ Dicho porcentaje subió hasta $16.1 \%$ en marzo del mismo año, y resultó que las exportaciones japonesas fueron impuestas a nivel más alto que el de los países signatarios del tratado de libre comercio.

Además, hay otro problema en cuanto a la maquiladora. Las industrias electrónicas habían gozado de dicho sistema, pero se abolió. El gobierno mexicano anunció una medida para promover las producciones por las industrias electrónicas como una alternativa que aliviaría los efectos contrarios de la abolición de dicho sistema. ${ }^{13}$ No obstante, dicha medida

Cuadro 1

\begin{abstract}
Japón
- Es la segunda economía más grande del mundo, con un pib nominal de 4290.7 mmd y un pib per cápita de 33 728 dólares en 2003.

- Es el décimo país más poblado del mundo con 127.2 millones de habitantes. Sin embargo, su población tiene una edad promedio de 42 años, por lo cual necesita localizar inversiones en otros países en donde la población sea joven y capacitada.
\end{abstract}

- Es la octava fuente de ied en el mundo, aportando un promedio anual de aproximadamente 26 mil millones de dólares entre 1994 y 2003.

- Es uno de los países con mayores tasas de ahorro en el mundo, aproximadamente $30 \%$ del pib durante la última década.

- Es un productor y exportador de elementos de alta tecnología con un importante valor agregado y salarios elevados, que requiere importar productos de tecnología media-alta como electrónicos, electrodomésticos y del sector automotriz.

- Importa el $60 \%$ de su consumo de alimentos, y no produce grandes cantidades de bienes para la exportación en este sector. Por lo tanto, requiere de un socio comercial que pueda brindarle calidad y variedad de productos alimenticios.
- Tiene una abundante mano de obra joven y capacitada que en promedio tiene 23 años.

- Se ha ubicado como un lugar ideal para la ied gracias, entre otros factores, a los acuerdos comerciales negociados. Según cifras de las Naciones Unidas, México es el tercer receptor de ied entre los países en desarrollo y el primero en América Latina. Sin embargo, México ha recibido sólo el $1.3 \%$ de la ied total proveniente de Japón entre 1994 y 2003.

- Es uno de los principales productores y exportadores de bienes de tecnología media-alta, como electrónicos, electrodomésticos y del sector automotriz.

- El sector agropecuario es uno de los que cuenta con mayor potencial exportador. Las importaciones totales de productos agropecuarios de Japón provenientes de México son aún poco sianificativas. 
no ofrecerá el mismo beneficio como el del régimen anterior. Por tal razón, los productos locales están perdiendo sus competitividades del precio, lo cual traerá como consecuencia reducir la incursión de las industrias manufactureras japonesas en el mercado mexicano.

Teniendo en cuenta las características mencionadas anteriormente y el desarrollo económico de ambos países, se ha firmado el AAE. Sus efectos económicos concretos se describirán más adelante. A continuación veremos la naturaleza del AAE.

\section{El AAE entre México y Japón}

\section{Naturaleza del acuerdo}

El pacto económico entre México y Japón utiliza la denominación del Acuerdo de Asociación Económica, a diferencia del tLCAN. De cualquier forma, el AAE es un tratado en el derecho internacional, por lo cual es posible que imponga a ambos países ciertos deberes y obligaciones.

Además, como este acuerdo muestra una integración regional entre México y Japón, tampoco sería impugnable su concordancia con la tendencia de la economía mundial. Lo importante es en qué grado se ha hecho dicha integración. Como veremos más adelante, el acuerdo en análisis elimina las trabas aduaneras de forma inmediata o paulatinamente; sin embargo, cada estado participante sigue conservando sus tarifas arancelarias frente a terceros países, y en dicho sentido sería pertinente dar a este acuerdo la naturaleza de "zona de libre comercio". ${ }^{14}$

La denominación AAE también incluye las disposiciones sobre la cooperación económica en paralelo a la promoción del libre comercio; de ahí que la integración económica entre ambos países no solamente forma un bloque económico y comercial que permite con mayor libertad la circulación de servicios y bienes, sino también intenta fortalecer una cooperación bilateral.
Este marco es parecido al del Acuerdo de Asociación Económica de México con la Unión Europea (UE), el cual entró en vigor en 2000. En las negociaciones de dicho acuerdo, la propuesta original de la UE introducía una liberalización total del comercio industrial, que representaba cerca del $93 \%$ de los intercambios de bienes en dos fases: el $82 \%$ inmediatamente y el $18 \%$ restante en 2003. México proponía un calendario más largo.

El artículo 24 del Acuerdo General sobre Aranceles Aduaneros y Comercio (GATT) estipula que en los tratados de libre comercio se deberá realizar la liberación de todos los bienes por principio. No obstante, el tratamiento de los bienes agrícolas en el acuerdo entre México y la ue toma una medida convencida de que la liberación se realizará paulatinamente en un tiempo determinado. ${ }^{15}$

El AAE entre México y Japón también ha tomado una forma similar a la que México adoptó en las negociaciones con la UE. Sin embargo, dicho acuerdo nuevo liberaliza el $95 \%$ de los intercambios de bienes entre México y la UE, y también se eliminan prácticamente todas las barreras al comercio de servicios. En este sentido, se afirma que el acuerdo entre México y la ue es compatible con los lineamientos sobre acuerdos de libre comercio de la Organización Mundial del Comercio (омc); el artículo 24 del Acuerdo General sobre Aranceles Aduaneros y Comercio y con el artículo 5 del Acuerdo General sobre el Comercio de Servicios. ${ }^{16}$ La misma lógica también se aplicaría al AAE entre México y Japón.

\section{O bjetivos y estructura del AAE}

Los propósitos del AAE son para promover la liberación del comercio e inversión, así como el flujo libre de personas para objetivos de negocio entre México y Japón. El propio acuerdo también intenta promover una cooperación económica comprensiva, la cual incluye la política de competición, el mejoramiento del ambiente de negocios y la cooperación bilateral en el área tanto de educación profesional y entrenamiento, como en la de soporte para las 
pequeñas y medianas empresas. El acuerdo contribuye a la complementariedad entre ambos países y fortalece las relaciones económicas bilaterales.

El AAE entre México y Japón no sólo es un instrumento comercial sino que, además de los componentes de un tratado de libre comercio, incluye disposiciones relativas a la cooperación bilateral que, desde el punto de vista de México, le permiten aprovechar de mejor manera la liberalización y la apertura de los mercados de bienes, servicios y capitales.

A continuación se señalan los aspectos principales del acuerdo: ${ }^{17}$

El propio acuerdo consta de 18 capítulos y lleva 177 artículos en total. Además, para enriquecer el contenido del acuerdo, hay 18 anexos relacionados con algunos capítulos. En esta estructura, los capítulos 3, 4, 5, 7, 11 y 14 llevan disposiciones abundantes relativas a los demás, por lo que se destaca la importancia de estos temas en el propio acuerdo.

Los puntos importantes del acuerdo son: reglas de origen; certificado de origen y procedimientos aduaneros; comercio de bienes; inversión; cooperación bilateral.

\section{Disposiciones principales del AAE}

\section{Aseguramiento de la calidad de los bienes}

1) Reglas de origen

El AAE en análisis prevé la eliminación de las tasas arancelarias sobre bienes originarios de México y Japón, en un período de transición (artículo 5). Entonces, será necesario que existan reglas para determinar cuáles bienes son susceptibles de recibir trato arancelario preferencial. Por ello, el propio AAE contiene las reglas de origen en su capítulo IV que disponen las normas para determinar si un producto exportado por una parte del acuerdo puede beneficiarse de las preferencias que éste otorga.

Dicha reglamentación será precisa para el intercambio libre de los bienes, al igual que otros tratados de libre comercio suscritos por México, y también esto se dirigirá a la promoción de la integración de procesos industriales entre los países participantes.

El principio de las reglas de orígenes dispone en el párrafo I del artículo 22 , lo cual estipula la manera de definir los bienes originarios. Además, en algunos casos, aparte de satisfacer el requisito de clasificación arancelaria, los bienes deberán cumplir otras reglas así como del valor de contenido regional y de los materiales. Para ello, el capítulo IV dispone otras normas para el cálculo, la eva-

Cuadro 2

Aspectos principales del acuerdo de asociación económica México-Japón

\begin{tabular}{ll}
\hline \multicolumn{1}{c}{$\begin{array}{c}\text { Tratado de Libre Comercio } \\
\text { (disposiciones comerciales) }\end{array}$} & \multicolumn{1}{c}{$\begin{array}{c}\text { Cooperación bilateral } \\
\text { (cap. XIV. arts. 139 a 149) }\end{array}$} \\
\hline - Acceso a mercados de bienes (cap. III, arts. 3 a 21) & - Industria de soporte \\
- Reglas de oriqen (cap. IV, arts. 22 a 38) & - Pequeñas v medianas empresas \\
- Certificado de origen y procedimientos aduaneros & - Promoción del comercio y la inversión \\
(cap. V, arts. 39 a 50) & - Ciencia y tecnología \\
- Salvaguardias (cap. VI, arts. 51 a 56) & - Educación v capacitación laboral \\
- Inversión (cap. VII, arts. 57 a 96) & - Turismo \\
- Servicios (cap. VIII y IX, arts. 97 a 112) & - Agricultura \\
- Compras gubernamentales (cap. XI, arts. 119 a 130) & - Propiedad intelectual \\
- Competencia (cap. XII, arts. 131 a 135) & - Medio ambiente \\
- Solución de controversias (cap. XV, arts.150 a 159) & - Mejoramiento del ambiente de negocios \\
\hline
\end{tabular}


luación y la definición de los bienes determinados (artículos 23 a 38).

\section{2) Certificado de origen}

Además de la evaluación de los bienes y las reglas de origen, se necesita la confirmación del trámite para evaluar los bienes, es decir, un certificado de origen de los bienes.

El AAE en análisis establece mecanismos claros y seguros en el capítulo V. De esta manera se garantizará que únicamente los productos de México o Japón se beneficien de las preferencias arancelarias que determina el AAE. Así, el certificado de origen tendrá por objeto confirmar que un bien que se exporte de un país participante al otro califica como un bien originario.

Dicho certificado será expedido por la autoridad gubernamental competente ${ }^{18}$ del país exportador, a petición escrita del exportador 0 bajo la responsabilidad del exportador, de su representante autorizado (párrafo II del artículo 39). Para ello, previo a la expedición de un certificado de origen, el exportador que lo solicite deberá demostrar a la autoridad gubernamental competente de la parte exportadora o a quien ella designe, que lo exportado califica como un bien originario (párrafo IV del artículo citado). Para dicha solicitud, la autoridad gubernamental competente o quien ella designe, expedirá un certificado de origen con posterioridad a la exportación de un bien (párrafo $\mathrm{V}$ del artículo citado).

El apartado VI del artículo citado habla del tratamiento de los casos de robo, pérdida o destrucción del certificado de origen. Por lo general, el idioma que se utiliza para el certificado de origen será el inglés (párrafo VII del artículo citado).

El capítulo V también establece las normas de la administración y aplicación del certificado de origen. El artículo 43 dispone los registros contables, por lo cual cada país participante del acuerdo se asegurará que la autoridad gubernamental competente o quien ella haya designado conserve un registro del certificado de origen expedido durante un período mínimo de cinco años, después de la fecha de expedición del certificado (párrafo II del artículo citado).

Dicha disposición tendrá el significado relativo al artículo 44, lo cual establece el trámite de la verificación del origen de los bienes. Dicho artículo estipula que para efectos de determinar si un bien importado de la otra parte con trato arancelario preferencial califica como un bien originario, la parte importadora podrá, por conducto de su autoridad aduanera, conducir una verificación de origen mediante los documentos dispuestos en el párrafo I del artículo 44.

\section{3) Procedimientos aduaneros}

Relacionado con los procedimientos mencionados, existen las obligaciones respecto a las importaciones y exportaciones. Cada parte del acuerdo requerirá a un importador que solicite trato arancelario preferencial para un bien importado de la otra parte que hagan ciertas declaraciones y manifestaciones estipuladas en el párrafo I del artículo 40. Cada parte se asegurará que un exportador o un productor que haya llenado y firmado un certificado de origen, y que tenga razones para creer que el certificado contiene información incorrecta, notifique, sin demora y por escrito, cualquier cambio que pudiera afectar la exactitud o validez del certificado de origen a todas las personas a quienes hubiere entregado el certificado, así como a su autoridad gubernamental competente o a quien ésta haya designado y a la autoridad aduanera de la parte importadora (primera mitad del párrafo I del artículo 41).

La notificación debida, a su tiempo, se enviará por uno de los métodos establecidos en el párrafo 4 del artículo $44 .{ }^{19} \mathrm{Si}$ lo anterior se lleva a cabo antes del inicio de una verificación referida en el artículo 44 y si el exportador o productor demuestra que él contaba con elementos para determinar razonablemente que el producto calificaba como un bien originario al momento de emitir el certificado de origen, el exportador o el productor no será sanciona- 
do por haber presentado un certificado incorrecto.

Como se ha aclarado hasta aquí, las normas en materia aduanera tanto del certificado de origen como de procedimientos aduaneros, se han establecido para que otorguen mayor seguridad a las operaciones de comercio de bienes entre los países relacionados, ofreciendo certidumbre y seguridad jurídica a los exportadores, los importadores y a los productos.

\section{Mayor circulación de los bienes}

\section{1) Comercio de bienes}

Uno de los asuntos principales del AAE entre México y Japón es el comercio de bienes, los cuales estarán asegurados por el procedimiento de las reglas y el certificado de origen como se acaba de mencionar.

Para la mayor circulación de los bienes entre ambos países, el acuerdo dispone que tanto México como Japón eliminarán o reducirán sus aranceles aduaneros sobre bienes originarios designados para tales efectos en su lista establecida en el anexo 1, de conformidad con los términos y condiciones ahí establecidos (párrafo I del artículo 5). Así, ambos países acordaron eliminar o reducir los aranceles aduaneros de los productos tanto agropecuarios como industriales. Los efectos y las cifras concretos de este asunto se tratarán más adelante.

Necesariamente, dicha disposición apunta a promover el comercio libre de los bienes entre los dos países y, por lo tanto, no se reconocen los impuestos a la exportación de una parte hacia la otra (artículo 6).

Además, para desarrollar o complementar dichas disposiciones, el artículo 7 estipula que ninguna de las partes impondrá o mantendrá ninguna prohibición ni restricción aparte de los aranceles aduaneros a la importación de cualquier bien de la otra parte, o a la exportación o venta para exportación de cualquier bien destinado a la otra parte (párrafo I del artículo citado). Así se establece la prohibición de las restricciones a la importación y exportación.

Por consiguiente, cada país participante del AAE otorgará a los bienes trato nacional de conformidad con el artículo 3 del GATT de 1994, y para tal efecto el artículo 3 del GATT de $1994^{20}$ se incorpora y es parte integrante de dicho acuerdo (párrafo I del artículo 3). El trato nacional se refiere, en este caso, al trato no menos favorable que el trato más favorable que los gobiernos tanto de México como de Japón concedan a cualesquier bienes similares o bienes competidores directos o sustitutos (párrafo II del artículo citado). Como se ha señalado en este acuerdo, así como otros tratados de libre comercio, se penetra el principio del trato nacional y la nación más favorecida.

\section{2) Inversión}

Para un mayor flujo de la IED de Japón hacia México, se necesita la firmeza del acuerdo acerca de la inversión y su promoción. El AAE, en su capítulo VII, dispone un conjunto de normas claras y precisas en materia de protección a la inversión que ofrece una mayor certidumbre a los flujos de capital y garantiza la seguridad jurídica.

El capítulo citado destaca la aplicación de los principios - los cuales son comunes en otros tratados de libre comercio-, el trato nacional y la nación más favorecida.

En cuanto al trato nacional, el párrafo I del artículo 58 dispone que cada parte otorgará a los inversionistas de la otra parte y a sus inversiones un trato no menos favorable que el trato que otorgue, en circunstancias similares, a sus propios inversionistas y a sus inversiones en lo referente al establecimiento, adquisición, expansión, administración, conducción, operación, mantenimiento, uso, disfrute y venta $u$ otra disposición de las inversiones. El significado del trato referido en dicha disposición se aclara en el párrafo siguiente del artículo citado, es decir, se refiere a un trato no menos favorable que el trato más favorable que México o Japón otorguen, en cir- 
cunstancias similares, a los inversionistas e inversiones de los inversionistas de la parte a la que se integran.

Acerca de la nación más favorable, el artículo 59 establece que cada parte otorgará a los inversionistas de la otra parte y a sus inversiones, un trato no menos favorable que el trato que otorgue, en circunstancias similares, a los inversionistas de un país que no sea parte y a sus inversiones, en lo referente a las actividades de inversión.

Por ambas disposiciones citadas, cada país participante del AAE otorgará a los inversionistas del otro país y a sus inversionistas el mejor de los tratos. Además, dichas disposiciones se complementan por el artículo 60, el cual establece el nivel mínimo de trato que debe otorgarse a las inversiones de los inversionistas de la otra parte al disponer que cada parte otorgará a las inversiones de los inversionistas de la otra parte un trato acorde con el derecho internacional, incluido trato justo y equitativo, así como protección y seguridad plenas.

Para efecto del mayor flujo de inversiones no debe existir algún requerimiento extraordinario. El AAE, para ello, dispone los requisitos de desempeño por los cuales ninguna parte podrá imponer ni hacer cumplir cualquiera de los siguientes requisitos, o hacer cumplir cualquier compromiso o iniciativa, en relación con el establecimiento, adquisición, expansión, administración, conducción u operación de una inversión, de un inversionista, de una parte o de un país no parte en su área, para realizar ciertos conductos estipulados en el párrafo I del artículo 65.

La sección 2 del capítulo VII establece un mecanismo para la solución de controversias en materia de inversión. Según el conjun- to de las disposiciones de dicha sección, un inversionista de una parte participante del AAE podrá someter una reclamación a arbitraje ${ }^{21}$ por cuenta propia, en el sentido de que la otra parte ha violado una obligación establecida en la sección 1 , y que el inversionista ha sufrido pérdidas o daños en virtud de la violación o a consecuencia de la misma, y al igual modo, someter una reclamación a arbitraje en representación de una empresa de la otra parte que sea una persona moral propiedad del inversionista o que esté bajo su control directo o indirecto, en el sentido de que la otra parte ha violado una obligación establecida en la sección 1 , y que la empresa ha sufrido pérdidas o daños en virtud de esa violación o a consecuencia de la misma (párrafo I del artículo 76).

En algunas ocasiones las controversias serán inevitables; no obstante, será deseable que su solución sea de manera amistosa desde el punto de vista de los objetivos del AAE. En este sentido, el artículo 77 dispone que las partes contendientes deberán intentar en primera instancia dirimir la controversia por vía de consulta o negociación.

Para el trámite del arbitraje se deberán cumplir los requisitos establecidos en el artículo 78, y una vez cumplidos, el inversionista contendiente podrá someter la reclamación a arbitraje de acuerdo con los métodos reconocidos internacionalmente que se disponen en el párrafo I del artículo 79.

Además, para la solución rápida de las controversias, cuando una parte contendiente considere que dos o más reclamaciones contengan una cuestión en común de hecho o de derecho, dicha parte podrá buscar que se determine la acumulación, de conformidad con los requisitos establecidos en el artículo 83 . 
El tribunal que se encarga de la solución de las controversias y sus miembros se establece conforme al artículo 82, y dicho tribunal llevará a cabo el procedimiento arbitral en un país que sea parte de la Convención de Nueva York (Convención de las Naciones Unidas sobre el Reconocimiento y Ejecución de las Sentencias Arbitrales Extranjeras, celebrada en Nueva York, el 10 de junio de 1958), salvo que las partes contendientes acuerden otra cosa (art. 88).

Como se ha señalado anteriormente, el propio AAE lleva varios reglamentos acerca de la inversión en miras a su mayor circulación. No obstante, la inversión no se reconoce ilimitadamente. De hecho, el artículo 66 establece el mecanismo de reservas y excepciones de la inversión. Además, el régimen de trato nacional, trato de nación más favorecida, como requisitos de desempeño no se aplicará a cualquier medida que una parte adopte o mantenga en relación con los sectores, subsectores 0 actividades, tal como se indica en la lista del anexo 7 (párrafo 3 del artículo 66). ${ }^{22}$

\section{Cooperación bilateral}

Los puntos que se han visto hasta aquí son de las esferas de la promoción del comercio en mayor parte. Aparte de ello, el AAE en análisis contiene otro asunto: cooperación bilateral. Con base en dicho asunto, ambos países del AAE deberán apoyarse en las nueve áreas establecidas en el capítulo XIV. En este sentido, se destaca el carácter "novedoso" de este acuerdo económico. Sobre todo, el convenio de la promoción de las pequeñas y medianas empresas (Pymes) es de mayor importancia e interés (artículo 141).

Según datos de la Secretaría de Economía de México, el objetivo principal de la cooperación bilateral en materia de las Pymes ${ }^{23}$ es aprovechar la experiencia de Japón para contribuir a elevar la competitividad de ellas, integrarlas a las cadenas productivas de empresas de mayor tamaño y promover su capacidad exportadora.
Japón lleva un modelo de subcontratación en el cual se desarrollaron las Pymes japonesas como proveedores componentes de las grandes empresas. Aparte de ello, existen varias políticas tanto jurídicas ${ }^{24}$ como financieras para fortalecer a las Pymes.

En México es muy reconocida la importancia de esta clase de empresas. Sobre todo en las décadas de los ochenta y noventa, se había dado una revaloración de las Pymes por sus posibilidades para afectar la reorganización de la producción, especialmente en el empleo, el PIB y la equidad. ${ }^{25}$ Sin embargo, por falta de apoyo crediticio y otros incentivos, el desarrollo de las Pymes en México no se ha logrado bien. Por lo tanto, a pesar de su importancia en la economía del país, siguen estando aisladas del área comercial externa. La causa de dichas desventajas provendría de la falta de economía de escala o los incentivos atractivos-reconocidos de varias clases brindadas por el sector público. No obstante, tanto Bancomext ${ }^{26}$ como Nafin, ${ }^{27}$ desde antes, han ofrecido varios apoyos para promover la exportación de parte de las Pymes para integrarlas en el comercio exterior, aunque su resultado hubiera sido bajo.

Un elemento vital que impide a las Pymes de México desarrollarse es la carencia del apoyo financiero. Al respecto, anteriormente a la concertación del AAE, Nafin y JBIC (Japan Bank of International Cooperation) suscribieron un contrato el 12 de agosto de 2003 para financiar la modernización de la planta productiva de las Pymes, con una cantidad de 250 millones de dólares.

Además, Jetro-México ha realizado recientemente una coordinación del Grupo de trabajo de la industria de soporte en el marco del "Foro de Colaboración para Pymes entre México y Japón”, establecido en 2001, y también envió expertos para Pymes en febrero de 2003 con el objeto de identificar y aclarar la problemática en la construcción de relaciones comerciales entre las empresas mexicanas y japonesas. $^{28}$ 
Así, ya se había impulsado un respaldo a las Pymes mexicanas que son proveedoras de grandes consorcios, a fin de fortalecer las cadenas productivas. Mediante la cooperación bilateral que se establece en el AAE, la oportunidad de aprovechar el sistema japonés en materia de las Pymes se agrandaría en la esfera tanto de transferencia de tecnología como de apoyo de aportación de capital.

\section{Perspectivas de los efectos económicos}

Para compensar los defectos o deméritos antes mencionados, y también teniendo en consideración que hoy en día México lleva un sentido importante como miembro del TLCAN y como lugar donde las industrias japonesas podrán asegurar una plataforma para el mercado de Norteamérica, la concertación del AAE con México, desde el punto de vista de Japón, generará varios méritos económicos.

A México también este acuerdo le daría varias oportunidades mediante las cuales, principalmente, se podrá diversificar el mercado de exportación, es decir el propio acuerdo podrá darle otro camino o dirección, ya que hasta la fecha se ha visto la dependencia en demasía hacia el mercado de Estados Unidos. ${ }^{29}$

A continuación, veremos las perspectivas de los efectos económicos del acuerdo para Japón y México.

Desde el punto de vista de Japón

Las ventajas económicas que ofrece el AAE firmado para Japón se dividirán en los tres puntos siguientes: 1) extensión del acceso al mercado de México; 2) eliminación de las desventajas competitivas para Japón; 3) aseguramiento a la puerta a Estados Unidos y América Latina.

1) Extensión del acceso al mercado de México Mediante el AAE Japón podrá ganar el acceso extendido al mercado mexicano, el cual está desarrollándose dinámicamente, con una población de alrededor de 100 millones y una escala económica localizada en el décimo lu- gar en el mundo (equivalente a la escala económica combinada de los diez países de la ASEAN).

Un examen sobre el AAE revela que la eliminación de la tarifa arancel podrá incrementar las exportaciones japonesas hacia México por $29.4 \%$, mientras desde México por $10.9 \%$. En resumen, la balanza comercial de Japón con México será esperada al crecimiento de $69.9 \% .^{30}$ Las importaciones de los productos agroalimentarios de México ofrecerían un suministro estable a los consumidores japoneses.

Asimismo, como se ha visto anteriormente, la eliminación de los requerimientos de desempeño podrá ser beneficiosa por la promoción de la inversión japonesa en México. Si México puede prometer firmemente esta clase de requerimientos en otros sectores en el futuro, se dará un efecto muy positivo para la inversión japonesa en México.

Por ejemplo, el AAE podrá ofrecer un beneficio de hacerles posible a los bancos o las compañías de seguro, que ya han estado en operación en México, transmitir la inversión directa en México desde Japón. Esto porque la forma actual de entrada al mercado mexicano a través de Estados Unidos mediante el TLCAN es costosa. ${ }^{31}$ Además, el AAE podría permitir a los bancos o las compañías de seguro entrar a México nuevamente.

Mediante el AAE México otorgará acceso inmediato a 44 fracciones arancelarias de productos japoneses, principalmente de alta tecnología, y se consolida el acceso con arancel de cero por ciento para Japón en ciertos productos así como equipos de telecomunicaciones, teléfonos, videocámaras, periféricos de cómputo, fotocopiadoras y reproductores de CD y DVD, entre otros. ${ }^{32} \mathrm{El}$ AAE podrá beneficiar a los consumidores, al existir productos que antes pagaban entre $18 \%$ y $30 \%$ de arancel de importación provenientes de Japón, y con el acuerdo pagarán cero arancel para los productos como juguetes electrónicos, videojuegos, instrumentos musicales electrónicos (órga- 
nos). Así, se dará la complementariedad de la economía entre México y Japón.

2) Eliminación de las desventajas competitivas para Japón. Este AAE permitirá a las empresas japonesas disfrutar del tratamiento igual con las de Estados Unidos, Canadá y la Unión Europea, en áreas como aranceles, servicios y compras del gobierno.

$\mathrm{Al}$ respecto, la eliminación del control de la inversión extranjera en varios sectores en que las empresas japonesas están interesadas podrá expandir la inversión por ellas. Dicho punto se dará con más eficiencia en el sector financiero como se ha señalado anteriormente. Las empresas japonesas que están en operación en dicho sector entran al mercado mexicano a través de sus subsidiarias en Estados Unidos. Por lo tanto, el AAE podrá permitirles entrar directamente a ellas que están subsidiadas en $100 \%$ por las compañías japonesas.

En el ramo automotriz (de interés para Japón pero de gran sensibilidad para México), se otorgó acceso inmediato sólo a una cuota equivalente a $5 \%$ del mercado nacional, y se desgravará totalmente seis años después. Puesto que el $60 \%$ de la exportación japonesa hacia México se convierte en coches hechos en México, en televisores hechos en México, en máquinas electrónicas de alta calidad hechas en México para exportarlas a otros mercados, si se realiza la desgravación a favor de Japón, le dará más oportunidad de incursar en otros mercados con condiciones competentes.

3) Aseguramiento a la puerta a Estados Unidos y América Latina. El AAE en análisis podrá permitir a Japón entrar en los mercados de Estados Unidos y América Latina (el continente tiene una población de 800 millones y se evalúa en 10 trillones de PIB) a través de México, ya que ha concluido los acuerdos de libre comercio con los 42 países incluyendo Estados Unidos, Canadá, los 25 países de la Unión Europea y otros países de América Latina.
Por ejemplo, la vista básica de las empresas japonesas de automóvil sobre México como una plataforma estratégica para el mercado de Estados Unidos se queda intacta. Sin embargo, el AAE debería permitirles exportar los coches lujosos o vehículos de la utilidad de deporte a México directamente, también las partes de auto no producidas en dicho país. Además, se permitirá un aumento de exportación de las demás partes de auto. Esto es porque, antes de la concertación del AAE, los vehículos completos importados desde Japón eran sujetos a la tarifa alta de 20-30\% (en cambio, la tarifa sobre importación desde los países del TLCAN es $3.3 \%$ en 2000). ${ }^{33}$

En resumen, el AAE entre México y Japón beneficiará a éste exportar los productos atractivos a los mercados alrededor de aquel país con un precio competitivo.

Por lo expuesto, el AAE ofrecerá a las actividades empresariales japonesas una oportunidad de repensar la estrategia dentro de México, así como la expansión de las inversiones directas en dicho país y reexaminar las bases de producción y exportación para México, otros países de América Latina y Estados Unidos.

\section{Desde el punto de vista de M éxico}

Desde el punto de vista de México, el mérito del AAE se concentraría en la expansión de la inversión ${ }^{34}$ desde Japón y en el incremento de las exportaciones.

1) Expansión de la inversión y su impacto en el empleo. Japón es una fuente importante de empleos por ser el octavo país inversionista del mundo, al invertir 26 mil millones de dólares promedio anuales durante el período 19942003. Sin embargo, México recibió solamente el $1.3 \%$ de la IED japonesa en el mundo en ese período. Dicha realidad reflejaría la mala experiencia de la crisis de la deuda externa de 1982 en México, lo cual influyó en la baja de IED por parte de Japón. ${ }^{35}$ No obstante, el acuerdo de esta vez generará una mayor certidumbre convencional para el inversionista japonés, 
por consiguiente, se esperará un incremento en los flujos de IED hacia México.

Según un examen de la Secretaría de Economía, ${ }^{36}$ se estima que con el acuerdo las exportaciones mexicanas hacia Japón podrían crecer a una tasa de $10.6 \%$ promedio anual. El crecimiento en las exportaciones e IED japonesa tendrán un importante impacto en el empleo: cerca de 41 mil plazas directas anuales y por lo menos otras 41 mil indirectas. En fin, por los dos factores generadores de empleo (tanto directo como indirecto), uno de ellos la inversión y otro las exportaciones, se estima que se generarán 82046 empleos (por aquel factor 26 646 y por éste 55400 ) anualmente. En la severa situación actual de desempleo de México, este AAE ofrecería una alternativa generadora del empleo. ${ }^{37}$

Aunque existan algunas desventajas para las empresas japonesas que están en operación en México, actualmente Japón es un proveedor importante de la industria maquiladora. Con el AAE se estima un mayor crecimiento de la industria manufacturera mexicana con insumos de gran calidad que están en posición de impulsar el crecimiento de cadenas productivas y generar un mayor valor agregado en la industria, así como la creación de más empresas y empleos mejor remunerados. También se crearía otro mérito si pudieran entrar efectivamente las instituciones financieras japonesas en el mercado mexicano, ya que para cualquier empresa es vital la fuente financiera para sus actividades.

Además de su potencial como inversionista, Japón es un proveedor importante de insumos y maquinaria con alto valor tecnológico que no compite en términos generales con los proveedores mexicanos. En dicho sentido, se daría una satisfacción de la vida de los ciudadanos mexicanos con los productos japoneses. $^{38}$

Se ha citado la expansión de exportaciones hacia Japón como otro efecto económico del AAE. Al respecto, se estima que se beneficiará el sector agroalimentario. Cambiando de la sección veremos los índices concretos.
2) Acceso a mercado japonés de bienes: enfocando los productos agroalimentarios. El AAE beneficiará principalmente al sector agroalimentario (Alejandro Guzmán Larralde, presidente del Consejo Agropecuario de Jalisco). ${ }^{39}$ Sobre todo, los productos cárnicos, las frutas, las hortalizas y el tequila serán los más beneficiados con el acuerdo comercial. Esta afirmación se basa también en que Japón no es autosuficiente en producción agrícola. Por lo tanto, habrá posibilidad de sacar provecho de este acuerdo, ya que México detenta apenas el $1 \%$ de ese mercado, calculado en $40 \mathrm{mil}$ millones de dólares (Mutsuyoshi Nishimura, embajador de Japón en México). ${ }^{40,41}$

Como se señaló anteriormente, con el AAE cada país participante deberá eliminar o reducir sus aranceles aduaneros sobre bienes originarios (párrafo I del artículo 5). Los términos, condiciones, clasificaciones y categorías de los mismos que se beneficiarán por el acuerdo se establecen en el anexo I del AAE. Dicho anexo se divide en tres secciones donde cada país estipula el calendario de la eliminación o reducción de los aranceles aduaneros. Por ser inmenso el contenido de dicho anexo, es conveniente analizar al respecto otras cifras que ofrece tanto la Secretaría de Economía de México como el Ministerio de Relaciones Exteriores de Japón.

Japón elimina aranceles en forma inmediata, a partir de la entrada en vigor del acuerdo, en $91 \%$ de las fracciones arancelarias. Como se ha mostrado, el sector más favorable por este AAE para México es el agroalimentario. A continuación veremos las cifras concretas al respecto.

Si se dividen los bienes relacionados según el tiempo de acceso, serán lo siguiente (ver cuadro 3).

Además, se había negociado otro acceso preferencial con cuotas para productos sensibles para Japón y de gran interés para el sector agroalimentario mexicano. Se obtuvieron cuotas especificadas en los siguientes productos: carne de puerco, carne de res, carne de pollo, jugo de naranja, naranja, miel, catsup, 
pasta, puré de tomate, jugo de tomate, salsa de tomate, dextrinas y sorbitol.

Los primeros cinco productos son principales en este sector. A continuación, veremos las cuotas acordadas (ver cuadro 4).

Incluyendo los productos señalados en las gráficas, México logró negociar compromisos en 796 líneas arancelarias, que representan más del 99\% de las exportaciones mexicanas hacia Japón.

Como se aclara en los párrafos precedentes, se puede afirmar que está abierto el mercado japonés para el sector agroalimentario mexicano mediante el AAE. No obstante, no se debe perder de vista que aunque se lograron ciertas cantidades o ventajas, si no se esfuerza el propio sector agrícola de México, no podrá aprovechar el mismo acuerdo efectivamente. Sin embargo, es indudable que se dará mucha oportunidad de incursar en el mercado de Japón para el sector agroalimentario mexicano. ${ }^{42}$
3) Otros sectores beneficiados y el efecto de la cooperación bilateral. El propio acuerdo ofrecerá el beneficio no solamente al sector agrícola sino también a otros sectores.

El acero ordinario japonés, que compite con la producción nacional, no se desgravará en los primeros cinco años de la vigencia del acuerdo, y se desgravará gradualmente en los segundos cinco años de vigencia del AAE. Los artículos especializados no producidos en México y usados en el sector automotriz se liberarán de inmediato (Fernando Canales Clariond, secretario de Economía).

Además, se aplicará cero arancel a las exportaciones mexicanas de calzado de cuero al entrar en vigor el acuerdo, y tendrá un cupo de hasta 250 mil pares con insumos no nacionales que se incrementará en $20 \%$ anual.

Las prendas de vestir fabricadas en México estarán libres de arancel a partir de la entrada en vigor del acuerdo, y habrá un cupo de 200 millones de dólares anuales para ropa cuya tela no sea de origen nacional. Al respecto,

Cuadro 3

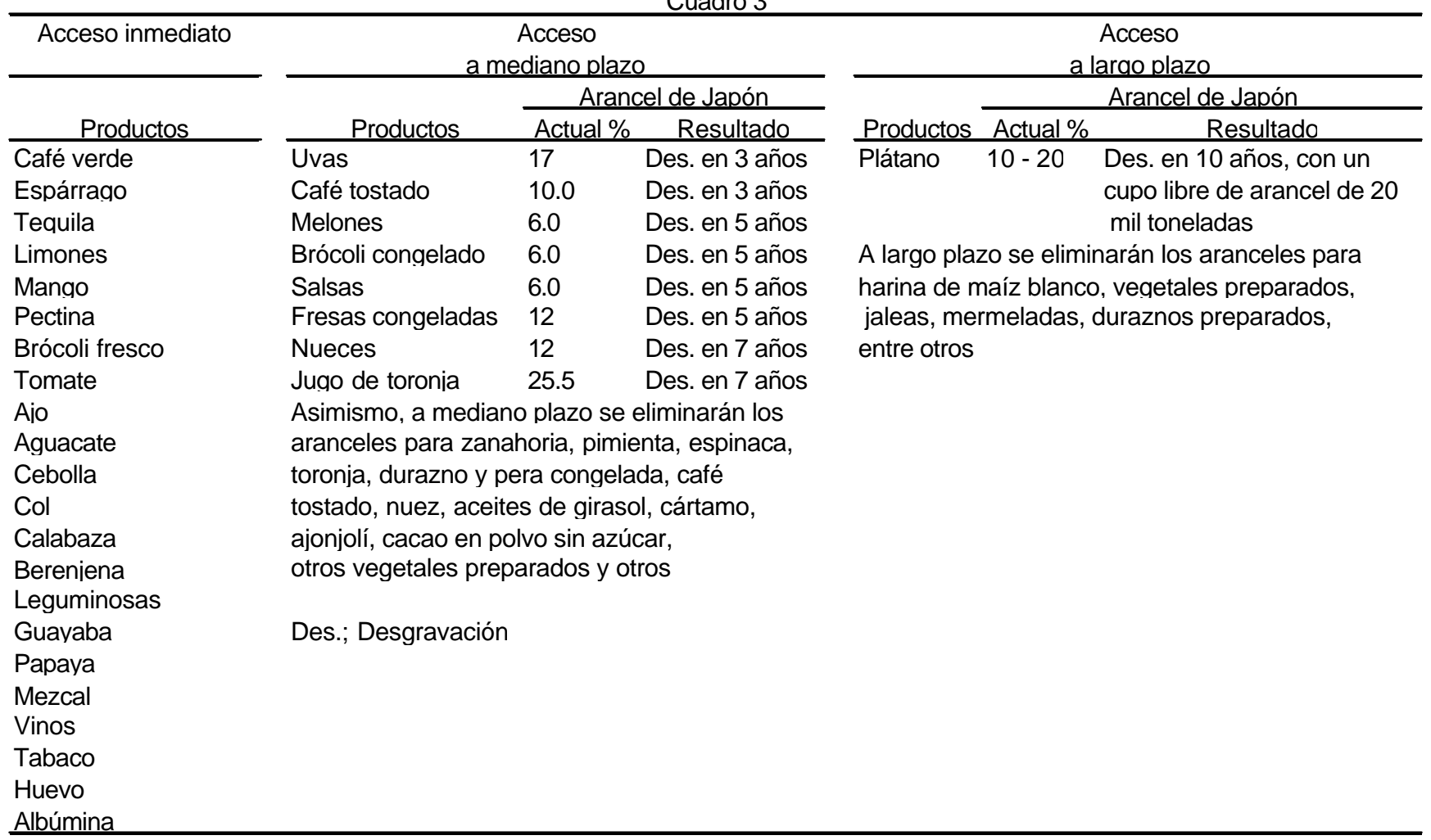

Fuente: Secretaría de Economía, México. 
Antonio Kuri (presidente de la Cámara Nacional de la Industria del Vestido) consideró que con este cupo el sector nacional podrá generar 20 mil empleos durante el primer año. ${ }^{43}$

El AAE será favorable para el sector químico de México, porque tendrá acceso preferencial a $91 \%$ de sus productos a partir del momento en que entre en vigor el acuerdo (José Luis Uriegas, presidente de la Asociación Nacional de la Industria Química). ${ }^{44}$

Todo lo expuesto es el efecto directo en la promoción del libre comercio. En paralelo a dicho efecto, el AAE tiene otro objetivo: la cooperación económica bilateral. En dicho sentido, es pertinente citar la afirmación del embajador mexicano en Tokio, Miguel Ruiz-Cabañas, quien destaca el carácter "novedoso" de este tratado de comercio al promover, por ejemplo, el protagonismo de las pequeñas y medianas empresas, las cuales son "la columna vertebral" de la economía de cualquier país. ${ }^{45}$

Como se ha señalado anteriormente, el sector más favorecido en el AAE para México será el agrícola. Según el Centro de Estudios Económicos del Sector Privado, México deberá aumentar su nivel tecnológico y producir bienes con mayor valor agregado nacional si pretende ser competitivo. ${ }^{46}$ Es decir, es importante estimar que México deberá aprovechar la inversión extranjera proveniente de Japón para mejorar la competitividad de los productos nacionales. En dicho sentido, es muy cierta la afirmación del coordinador del Consejo de Cámaras Industriales de Jalisco, Tomás López Miranda, quien destaca que "la mayor petición a los tres poderes es que se requiere fortalecer las cadenas, si no, no tenemos capacidad real de competir, y nos quedamos fuera de la jugada", y también dice que "las oportunidades en Estados Unidos, en Europa y en Asia están, pero si no tenemos el soporte de país competitivo, ¿con qué las tomas?”. ${ }^{47}$

\section{Conclusión}

Este artículo ha expuesto la relación histórica, el proceso, las perspectivas económicas y la sinopsis del AAE que se firmó recientemente entre México y Japón.

$\mathrm{Al}$ recordar la historia, ambos países han mantenido la relación amistosa. México ha llevado a cabo la concertación de varios tratados de libre comercio con diversos países positivamente. El TLCAN era un motivo por el cual Japón deseaba firmar este AAE lo más pronto posible, porque tendría una base en México para entrar a otros mercados del continente americano. Japón dio un viraje en la política exterior recientemente y se desvió de la política del comercio exterior multilateral que promovía GATT (OMC), y comenzó a acelerar tratados de libre comercio bilateral.

El AAE es el segundo acuerdo de esta naturaleza para Japón. Por esta oportunidad, Japón tiene una visión de promover la concertación de los tratados de libre comercio con otros países asiáticos en lo futuro, lo cual será favorable para México en punto de vista de incursar en los mercados de dichos países.

Cuadro 4

\begin{tabular}{lccc}
\hline \multicolumn{1}{c}{ Productos } & \multicolumn{2}{c}{ Cuotas (toneladas) } & Quinto año \\
\hline Carne de puerco & Primer medio año & 80,000 \\
Jugo de naranja & 38,000 & 6,500 \\
& 4,000 & Tercer año & Quinto año \\
Carne de res & Primeros dos años & 3,000 & 6,000 \\
Narania & 10 (no arancel) & 2,000 & 4,000 \\
& 10 (no arancel) & Segundo año & Quinto año \\
\cline { 2 - 4 } Carne de pollo & Primer año & 2,500 & 8,500 \\
\hline
\end{tabular}

Fuente: Ministerio de Relaciones Exteriores de Japón. 
En las negociaciones del AAE, un punto de discusión era la mayor posibilidad de intervenir de parte de México en el mercado agrícola de Japón. Se podría decir que en dicho punto México ha logrado un avance exitoso. Además, en ellas se utilizaron las medidas de la eliminación paulatina de aranceles, las cuales también se emplearon en las negociaciones con la UE.

El contenido del propio AAE sería similar al de otros tratados. Sin embargo, lo notable sería la disposición clara sobre la cooperación económica en materia de las Pymes. Dicho punto era un pendiente de parte de México en las negociaciones con la uE. ${ }^{48}$ Mediante dicha cooperación se podría esperar el desarrollo de las Pymes mexicanas, las cuales sostienen la base de su economía. Esto se realizará con tal de que se expanda la economía de escala en México, es decir, dependería de cómo las empresas mexicanas pueden aprovechar esta oportunidad con una postura seria, por lo tanto, primero, ellas deberían desarrollar sus actividades con una base firme.

Las exportaciones de ciertos productos de parte de Japón mediante el AAE tendrán mucha importancia en la vida de los mexicanos. Además, se aumentará la transferencia de tecnología desde Japón a través del AAE, lo cual será una buena ocasión para que las empresas mexicanas se desarrollen utilizando la tecnología japonesa. ${ }^{49}$ Para generar dichos méritos lo más posible, el propio AAE establece los principios de la promoción del comercio exterior y la cooperación bilateral. Sin embargo, se necesitará la realización apropiada de las políticas tanto económicas como jurídicas en ambos países. Como dispone el AAE en análisis, la protección al derecho intelectual será un ejemplo, la cual ofrecería un efecto de mayor flujo de la inversión de Japón a México.

La IED de Japón a México ha experimentado un aumento positivo desde la década de los sesenta. Pero pareciera que hay dificultades para el entendimiento mutuo por la diferencia de la cultura y las costumbres. ${ }^{50}$ Esperamos que avance la comprensión y cooperación recíproca con motivo de la concertación del AAE entre México y Japón en lo futuro.

\section{Notas}

1 Para la situación relativa al comercio de Japón con otros países incluyendo México, véase: CEPAL, Nuevas políticas comerciales en América Latina y Asia, algunos casos nacionales, CEPAL, Santiago de Chile, 1997; Carnegie endowment for international peace, Japan and the United Nations, Manhattan Publishing Company, New York, 1958; Stallings, Barbara y Székely, Gabriel (comps.) Japón, los Estados Unidos y la América Latina, Fondo de Cultura Económica, México, 1994; Blandon, P. R., Japan and world timber markets, Cabi publishing, U. K., 1999; Instituto Matías Romero de Estudios Diplomáticos, La apertura de México al Pacífico, Secretaría de Relaciones Exteriores, México, 1990; Lozoya, Jorge Alberto, Japón 1946-1990: el camino a la opulencia, Instituto Matías Romero de Estudios Diplomáticos, México, 1990.

2 Es un acuerdo de asociación económica en el cual se eliminan los aranceles para facilitar la transmisión de los bienes y la inversión entre Japón y Singapur. Al igual que el AAE en análisis de este artículo, el acuerdo entre Japón y Singapur no solamente apunta la liberación del comercio exterior sino también la cooperación económica en materia de tecnología de comunicación y turismo. En este marco, Singapur ofrece el 0\% de aranceles para el $100 \%$ de los bienes, mientras que Japón ofrece $94 \%$.

3 Acerca de la historia de Japón, ver: Kaibara Yukio, Historia de Japón, Fondo de Cultura Económica, México, 2000.

4 Entrando a la nueva edad Meiji, el tema principal que ocupó al gobierno de esta época era tratar de abolir los tratados desiguales. Pero el obstáculo máximo para eso era el hecho que no existía el derecho civil que había disciplinado los derechos fundamentales de los ciudadanos. Por lo tanto, para pedir la abolición de los tratados, era necesario que se redactara el derecho civil que disciplinara las relaciones jurídicas fundamentales de la vida humana. Aquí surgieron las sucesiones de los derechos occidentales principalmente, y esto se hizo la razón con la que califican al derecho japonés como jurídico romanista después.

5 Kerber Palma, Víctor, Sushi con tortilla: relaciones entre México y Japón, 1995-2000, Foro internacional, XLI4, octubre-diciembre de 2001, p. 863.

6 Recientemente, en 1999 se comenzó la New JapanMexico Comision for the 21th Century, la cual estaba esperada a presentar un conjunto de recomendaciones para fortalecer las relaciones bilaterales de ambos países.

7 Este informe final menciona los antecedentes, las perspectivas y los problemas que deberían solucionarse al concertar el acuerdo entre México y Japón. El archivo, que se encuentra en formato PDF, se puede consultar en la página Web de la Secretaría de Economía; http:// 
w w w . e conomia-s n ci.gob.mx/sic_ph p/ ls23al.php?s=516\&p=1\&l=1.

$8 \mathrm{Al}$ igual que el informe realizado por el Grupo de estudio México-Japón sobre el fortalecimiento de las relaciones económicas bilaterales en México, el reporte que cumplió el Jetro hace mención a las ventajas de concertar el acuerdo con México desde el punto de vista de Japón y los problemas que existían ese entonces en los negocios de las empresas japonesas encontradas en México. Dicho archivo, que se encuentra en formato PDF, se puede conseguir en la página Web de Jetro de Japón; http://www.jetro.go.jp/ec/e/report/fta_mexico/fta.pdf

9 "Firman hoy Fox y Koizumi el acuerdo comercial, liberación total, en 20 años", El Universal, en Internet, 17 de septiembre de 2004.

10 "México y Japón firmaron el acuerdo de asociación económica", Es más (servidor de Internet), 17 de septiembre de 2004; http://www.esmas.com/noticierostelevisa/ mexico/392154.html.

11 “Por qué es bueno un Acuerdo de Asociación Económica (AAE) con Japón?”, 10 de marzo de 2004. Dicho dato se puede conseguir en la página Web de la Secretaría de Economía de México: http://www.economiasnci.gob.mx/sic_php/ls23al.php?s=516\&p=1\&l=1.

12 Jetro, Report on closer economic relations between Japan and Mexico, p. 4.

13 Desde antes ha sido un problema la tarifa alta de aranceles para las empresas japonesas que se encontraban en México, si bien fue atendida en México con los Programas Sectoriales (PPOSEC), creados para eliminar o reducir los aranceles de insumos, partes, componentes y maquinaria y equipo, así como para mantener la competitividad de la industria. Los beneficiarios de dicho programa son todos los eslabones de cadenas productivas de los sectores involucrados, puesto que les permite importar bienes libres de arancel o con impuestos bajos de países que no son miembros del TLC.

14 El grado de integración será determinado por los compromisos que los países participantes adquieren al concertar los acuerdos de integración. Según el agrupamiento por el tratadista Jorge Witker, los acuerdos se dividen en cinco tipos: a) tráfico fronterizo; b) zona de libre comercio; c) unión aduanera; d) mercado común; y e) unión económica, conforme al grado de integración. En su afirmación, por el acuerdo de la zona de libre comercio se eliminan los derechos aduaneros, todas las reglamentaciones comerciales restrictivas como pueden ser cupos o cuotas, licencias, permisos previos, etcétera, respecto al intercambio de los productos originarios de los países integrantes de la misma. Véase Witker, Jorge, Régimen jurídico del comercio exterior, unam, México, 1991, p. 34 y ss. Sin embargo, al ver el contenido del AAE en análisis, se establece en parte algunas cuotas de las exportaciones e importaciones. En este sentido, podría ser que no concuerde con el concepto de zona de libre comercio en general del AAE entre México y Japón. No obstante, dicho acuerdo será más similar a este concepto que otros.

$15 \mathrm{Al}$ respecto, el tratadista Shouji Nishijima había afirmado que esta manera pragmática sería un ejemplo en las negociaciones entre México y Japón. Nishijima,
Shouji, Se está moviendo el tratado de libre comercio entre México y Japón, WorldAffairs Weekly, 10 de abril de 2002, ллл press. Dicho artículo se puede leer en la página Web de la Universidad de Kobe: http:// www.rieb.kobe-u.ac.jp/ nisijima/wwindex $2 . h t m l$.

16 Instituto de Relaciones Europeo-Latinoamericanas, "El acuerdo México-uE, pieza clave de una asociación integral”, el cual es el artículo que se encuentra en la página Web de la SELA: http://sela2.sela.org/.

17 Esta información se basa en el documento de la Secretaría de Economía de México titulado "Acuerdo de asociación económica entre México y Japón”, el cual se encuentra en formato PDF y se puede conseguir en la página Web de la secretaría citada.

18 La autoridad gubernamental competente de la parte exportadora se encarga de realizar los siguientes asuntos (párrafo IX del artículo 39): a) determinará los mecanismos administrativos para la expedición del certificado de origen; b) proveerá, a petición de la parte importadora de conformidad con el artículo 44 información relativa al origen de los bienes para los cuales se haya solicitado trato arancelario preferencial; y c) proveerá a la otra parte, los modelos de sellos utilizados por las oficinas de la autoridad gubernamental competente o quien ella haya designado, para la expedición del certificado de origen. Así, dicha autoridad deberá establecer el modelo del certificado por lo cual se asegurará la confirmación de la característica o naturaleza de los bienes. Los importadores, exportadores y productores, que proporcionan a su autoridad aduanera, autoridad gubernamental competente o a quien ella designe, declaraciones o documentación falsa relacionada con el certificado de origen, se deberán imponer algunas sanciones (artículo 46).

19 La autoridad aduanera de la parte importadora enviará los cuestionarios a que se refiere el inciso 1 (b) a los exportadores o productores en la parte exportadora, por cualquiera de los siguientes medios:

a) correo certificado que confirme su recepción;

b) cualquier otro método que confirme la recepción por el exportador o productor;

c) cualquier otro método que las partes acuerden.

La autoridad aduanera de la parte importadora comunicará de inmediato a la autoridad gubernamental competente de la parte exportadora, toda vez que envíe un cuestionario conforme al inciso 1 (b).

20 El término “GATT 1994” significa el Acuerdo General sobre Aranceles Aduaneros y Comercio, determinado en el Anexo IA del Acuerdo de Marrakech, por el que se establece la Organización Mundial del Comercio (hecho en Marrakech el 15 de abril de 1994, con sus reformas). Para efectos de este acuerdo, las referencias a los artículos del GATT 1994 incluyen las notas interpretativas.

21 En cuanto al arbitraje internacional, véase Briseño Sierra, Humberto, El arbitraje comercial, $2^{\mathrm{a}}$ ed., Limusa, México / España / Venezuela / Colombia, 1999; Gorjón Gómez, Francisco, Arbitraje comercial y ejecución de laudos, McGraw-Hill, México, 2000; Uribarri Carpintero, Gonzalo, El arbitraje en México, Oxford, 1999. 
$22 \mathrm{El}$ anexo 7 establece las reservas en otras materias de tanto comunicaciones como energía, y sus elementos de agrupación son similares a los del anexo 6. En el anexo 7 se reconocen las reservas de once asuntos de parte de Japón y catorce de México. Además, el anexo 8 se refiere a las actividades reservadas al estado. En dicho anexo se establecen las reservas sensibles para México como las de otros tratados de libre comercio. Las principales son: petróleo, otros hidrocarburos y petroquímica básica; electricidad; energía nuclear y tratamiento de minerales radiactivos; servicios de telégrafo; servicios de radiotelegrafía; servicio postal; emisión de billetes y acuñación de moneda; control, inspección y vigilancia de puertos marítimos y terrestres; y control, inspección y vigilancia de aeropuertos y helipuertos. En cuanto a las reservas o excepciones de la inversión se deberán considerar las disposiciones de los anexos 6 y 9. La principal base jurídica de estas reservas de México tanto del anexo 7 como del 8 es, como muy reconocida, de los artículos 25, 27 y 28 de la Constitución Política del país. Se basan también en la Ley de Inversión Extranjera. En cuanto al tratamiento jurídico de la inversión extranjera de México, véase: Díaz, Luis Miguel, Inversión extranjera, derecho mexicano y derecho internacional, Themis, México, 2000.

23 Según las informaciones de la Secretaría de Economía y la Comisión Intersecretarial de Política Industrial (la cual data de febrero de 2004), las cuales se basan del censo económico 1999 del IneGi, las Pymes de México representan $99.7 \%$ de establecimientos, emplean a $79 \%$ del personal ocupado y generan $63 \%$ de PIB; http://www.cipi.gob.mx/Docs/Informaciondeprog/ PresentaCIPI.pdf.

- h t t p : / / w w w . c o n t a c to p y m e.g o b. m x/ impactopymes.asp?Lenguaje $=0 \&$ Cve_B $=5$.

Sin embargo, el criterio de estratificación de empresas se realiza conforme al de la ley del desarrollo de la competitividad de la micro, pequeña y mediana empresa (publicada en el Diario Oficial, el lunes 30 de diciembre de 2002: véase la nota 5). Por lo tanto, si hubieran ajustado las informaciones con el criterio vigente, no habría problema, si bien, si no lo hubieran hecho, habría alguna desviación entre las cifras de la Secretaría de Economía y del resultado del censo económico del INEGI.

Actualmente, acerca de la definición de las Pymes, en la ley de desarrollo de la competitividad de la micro, pequeña y mediana empresa (publicada en el Diario Oficial, fechado lunes 30 de diciembre de 2002), parten de los siguientes criterios, en número de trabajadores o empleados: micro: 0-10 (industria; comercio; servicios); pequeña: 11-50 (industria): 11-30 (comercio): 11-50 (servicios); mediana: 51-250 (industria): pequeña: $31-100$ (comercio): mediana: 51-100 (servicios).

24 Por ejemplo, recientemente se ha creado el régimen de sociedades confirmadas (no la forma jurídica de sociedades, sino la modalidad). Al respecto véase: Okabe, Taku, "Posibilidad de negocios en Japón, a partir de las reformas del derecho mercantil", México y la Cuenca del Pacífico, vol. 6, núm. 19 / mayo-agosto de 2003, De- partamento de Estudios del Pacífico de la Universidad de Guadalajara, México, 2003.

25 En cuanto a las propias Pymes en México véase: Rodríguez Valencia, Joaquín, Administración de pequeñas y medianas empresas, quinta ed., Thomson, Australia / Brasil / Canadá / España / Estados Unidos / Reino Unido / Singapur, 2002; Suárez Aguilar, Estela y Rivera Ríos, Miguel, Pequeña empresa y modernización: análisis de dos dimensiones, UnAM, México, 1994; Universidad Autónoma Metropolitana-Azcapotzalco, División de Ciencias Sociales y Humanidades, Perspectivas de la empresa y la economía mexicana frente a la reestructuración productiva, UAM, México, 1995; Basave Kunhardt, Jorge (coord.) Empresas mexicanas ante la globalización, Porrúa, México, 2000; Pueda Peiro, Isabel, Las micro, pequeña y mediana empresas en México: importancia, entorno, asociación y subcontratación, Asociación y cooperación de las micro, pequeñas y medianas empresas, México, Chile, Argentina, Brasil, Italia y España, Porrúa, México, 1999.

26 En la página Web de Bancomext, se presentan varias políticas que promueven a las Pymes; www.bancomext.mx. Las políticas que toma Bancomext tienden a promover las exportaciones de parte de las Pymes.

$27 \mathrm{Al}$ igual que Bancomext, en la página Web de Nafín se ofrecen varios apoyos a las Pymes:

http://www.nafin.com/portalnf/. Los apoyos de Nafin atienden a las Pymes en la esfera financiera en mayor parte. Según la información de la Secretaría de Economía, los programas que Nafin ofrece actualmente son los siguientes: créditos a tasa fija; créditos a tasa variable; desarrollo de proveedores del sector privado; programa de garantías. Todos están dirigidos a la producción y comercialización de pequeñas y medianas empresas. En este libro se presentan los servicios actuales de Nafin divididos en doce programas: Herrera Avendaño, Carlos, Fuentes de financiamiento, $2^{\mathrm{a}}$ ed., Sicco, México, 2003.

28 Jetro México, Contribución para México de un fortalecimiento de las relaciones económicas entre México y Japón, noviembre de 2003. Dicho dato se puede conseguir en la página Web de Jetro México; http:// www.jetro.org.mx/aae_mexico_japon.htm.

29 Japón ocupa el cuarto lugar mundial como importador, al registrar 381 mil millones de dólares durante 2003, creciendo a una tasa anual de $4.7 \%$ en los últimos diez años. El mercado de dicho país le dará a México otra opción de exportación. Cifras de la Secretaría de Economía: “¿Por qué es bueno un Acuerdo de Asociación Económica (AAE) con Japón?".

30 Jetro, Report on closer economic relations between Japan and Mexico, p. 7.

31 Jetro, op. cit., p. 8.

32 Esta descripción se basa en el dato de la Secretaría de Economía, “¿Por qué es bueno un Acuerdo de Asociación Económica (AAE) con Japón?”.

33 Jetro, op. cit., pp. 9 y 10.

34 Acerca de la importancia reciente de la inversión en México, véase el siguiente comentario breve: De la Calle Pardo, Luis, "The importance of foreign direct 
investment in the economic development of Mexico", Global forum on International Investment, New Horizons for Foreign Direct Investment, OECD, 2002.

35 Kerber Palma, Víctor, op. cit., pp. 863 y 864.

36 Esta descripción se basa en el dato de la Secretaría de Economía: “¿Por qué es bueno un Acuerdo de Asociación Económica (AAE) con Japón?”.

37 La inversión japonesa crecerá a un ritmo anual de mil 300 millones de dólares, y se generarán 270 mil empleos en un período de diez años (Fernando Canales Clariond, Secretario de Economía). Pues dicha cantidad se refiere, según el citado encargado, sólo a los puestos de trabajo vinculados con el sector exportador, pero sumados a las plazas vinculadas a la IED y a los empleos indirectos se generarían 820 mil plazas en diez años. "Ven inicio del TLc México-Japón en el 2005: LasE estima que la inversión japonesa en México crecerá a un ritmo anual de mil 300 millones de dólares, y que se generarán 270 mil empleos en...", Mural en Web, 11 de marzo de 2004.

38 Japón eliminará aranceles a 95 por ciento de las fracciones negociadas, mientras que México hará lo mismo en 44 por ciento de los rubros acordados mediante lo cual las exportaciones de México a Japón podrían crecer 10. 6 por ciento anual (Fernando Canales Clariond, citado Secretario de Economía). Necesariamente las exportaciones japonesas a México se incrementarán, sin embargo, esto no significará una sustitución de bienes nacionales por japoneses sino una división de labores o producciones, es decir, mientras México produce bienes primarios, los japoneses bienes intensivos en tecnología y capital, por lo que la balanza comercial seguirá siendo negativa. Ibid.

39 "Beneficia a agroindustria el acuerdo TLC con Japón: Evitan errores que se cometieron en tratados pasados", Mural en Web, 11 de marzo de 2004.

40 "Destaca Japón beneficios", Mural en Web, 11 de marzo 2004. No obstante, no se debe de olvidar la advertencia del citado embajador de que "ofrecer cupos no significa aumento de exportaciones, hay que hacer esfuerzos de vinculación, conocer el mercado y hay que conseguir que los productos lleguen en tiempo y con buena calidad".

$41 \mathrm{El}$ AAE en análisis es el primer tratado inclusivo hasta el sector agrícola para Japón. Como indica dicha circunstancia, es inmensa la ampliación de parte de Japón para las exportaciones agropecuarias mexicanas mientras existen críticas fuertes del sector agrícola de Japón. Véase; “A proteger carne de puerco de Japón”, Periódico Akahata en Web, 24 de noviembre de 2003. Dicha ansiedad es razonable como muestran las experiencias del TLCAN de que con el transcurso del tiempo la dependencia del sector agrícola de México hacia Estados Unidos se ha hecho alta en paralelo a la derrota sucesiva de dicho sector en México. Al respecto, el primer ministro Junichiro Koizumi destacó el significado o la importancia del acuerdo económico en la entrevista después de la firma declarando que "cada país tiene esferas positivas al igual que negativas. (En las negociaciones) es importante mantener un equilibrio amplio abiertamente, no reducido cerradamente". "Se firmó el tratado de libre comercio, el primer acuerdo inclusivo, se entrará en vigor desde abril del próximo año" $h$, Periódico Sankei en Web, 18 de septiembre de 2004. Además, en cuanto al cupo de carne de cerdo, se ha aclarado hasta el 17 de septiembre de 2004 que el gobierno japonés iba a tomar una medida urgente de la subida de la tarifa arancelaria para la exportación de carne de cerdo excepto la de México. Se prevé la oposición de parte de Dinamarca y Estados Unidos de América, los cuales están en competencia con México. "Se excluirá la carne de puerco de México, reconsideración de aranceles emergentes por razón del tratado de libre comercio", Noticia Kyodo en Web, 17 de septiembre de 2004.

42 Este punto se ha dado cuenta desde antes. La doctora Melba Falck ha investigado por un largo tiempo el sistema agrícola de Japón. La profesora, teniendo en cuenta las circunstancias en las que está Japón y la capacidad de México, destaca que se podría sacar provecho del sector agrícola de aquel país, afirmando lo siguiente: "La economía japonesa es nueve veces más grande que la mexicana, y recientemente dicho país se convirtió en el mayor importador de alimentos del mundo. En tal situación, también, se puede observar que a pesar de su potencial, la recesión de los años noventa que forzó a las mujeres a buscar trabajo fuera del hogar para complementar el ingreso, lo que incrementó las compras de alimentos preparados y congelados, y el comer fuera de casa. Por su parte, México, en los años 90s duplicó el valor de sus exportaciones agrícolas para llegar a un nivel de 8 mil millones de dólares en el 2000. Sin embargo, las exportaciones agroalimentarias hacia Japón queda escasas. Esto significa que México está dejando pasar oportunidades muy importantes en este mercado alimentario y que casi la totalidad de las ventas agrícolas al exterior están concentradas en un solo mercado, el de Estados Unidos". Falck, Melba, "Las relaciones económicas bilaterales México-Japón”,México y la Cuenca del Pacífico, vol. 5, núm. 16 / mayo-agosto de 2002, Departamento de Estudios del Pacífico, del Centro Universitario de Ciencias Sociales y Humanidades, de la Universidad de Guadalajara, México, 2002. También véase; Falck, Melba y Roberto Hernández, "Políticas agrícolas en China y Japón, implicaciones para México", México y la Cuenca del Pacífico, vol. 49, núm. 7 / julio de 1999. La doctora Falck indica los beneficios del alto grado de desarrollo de la tecnología japonesa y los elevados niveles de inversión en el extranjero. No obstante, no se trata nada más de aprovechar la transferencia de tecnología de Japón (aun no especifica cuál tecnología sería), sino de emular el "modo de hacer las cosas" de las empresas japonesas. Afirmando así, cita el caso del modelo de subcontratación japonés en que se desarrollaron las Pymes japonesas. En cuanto al sistema de innovación de Japón, incluyendo el desarrollo de la tecnología japonesa, es interesante la siguiente obra: Varela Petito, Gonzalo, Sistemas de innovación: una comparación entre Japón y México, Foro internacional, XLII-1, enero-marzo de 2002.

43 "Ven inicio del Tuc México-Japón en el 2005: La SE estima que la inversión japonesa a México crecerá a un ritmo anual de mil 300 millones de dólares, y que se 
generarán 270 mil empleos en....”, Mural en Web, 11 de marzo de 2004.

44 "Favorece a química el TLC con Japón: La negociación del TLC con Japón fue favorable para el sector químico del País", Mural en Web, 26 de marzo de 2004.

45 "Japón y México sellarán amistad estratégica con tratado comercio", EFE en Web, 10 de septiembre de 2004.

46 "Llama IP a aprovechar el TLC con Japón: Las áreas de negocio son agrícola, textil y calzado: CEESP”, El universal en Web, 5 de abril de 2004.

47 "Beneficia a agroindustria el acuerdo TLC con Japón: evitan errores que se cometieron en tratados pasados", Mural en Web, 11 de marzo de 2004.

48 Véase; Instituto de Relaciones Europeo-Latinoamericanas, ob. cit.

$49 \mathrm{Al}$ respecto, el doctor Kidana, haciendo mención de la transferencia de tecnología entre Japón y los países en desarrollo, afirma que se necesitan estudios sobre la tecnología necesaria en el país contraparte, el sistema jurídico y su establecimiento, y el entrenamiento de las personas para crear el mercado de tecnología. Kidana, Shoichi, El avance del derecho de la propiedad intelectual en Asia - globalización de mercados después de la creación de WTO trRIPs y su influencia. Las reformas del derecho económico de los países en desarrollo y la globalización (compilado por Imaizumi, Shinya), Instituto de economías en desarrollo (Ajia Keizai Kenkyuzyo), Japón, 2005, pp. 88 y 89.

50 Hay un libro que trata de la cooperación económica y el establecimiento de la relación de amistad entre Japón y los países de América Latina: Kawata, Tadashi, Usui, Mikoto y Ookuma, Tadauyki (comps.) Desarrollo económico y la transferencia de tecnología - enfocando la industrialización de América Latina, Instituto nacional de investigación de los problemas internacionales (Nihon Kokusai Mondai Kenkyuzyo), Japón, 1983.

\section{Bibliografía}

Basave Kunhardt, Jorge (coord.) Empresas mexicanas ante la globalización, Porrúa, México, 2000.

Blandon, P. R., Japan and world timber markets, Cabi publishing, U. K., 1999.

Briseño Sierra, Humberto, El arbitraje comercial, 2a ed., Limusa, México / España / Venezuela / Colombia, 1999.

Carnegie endowment for international peace, Japan and the United Nations, Manhattan publishing company, New York, 1958.

CEPAL, Nuevas políticas comerciales en América Latina y Asia, algunos casos nacionales, CEPAL, Santiago de Chile, 1997.

De la Calle Pardo, Luis, The importance of foreign direct investment in the economic development of Mexico, Global forum on international investment, new horizons for foreign direct investment, OECD, 2002.

Díaz, Luis Miguel, I nversión extranjera, derecho mexicano y derecho internacional, Themis, México, 2000.
Falck, Melba, "Las relaciones económicas bilaterales México-Japón", México y la Cuenca del Pacífico, vol. 5, núm.16 / mayo-agosto de 2002, Departamento de Estudios del Pacífico, del Centro Universitario de Ciencias Sociales y Humanidades, de la Universidad de Guadalajara, México, 2002.

Falk, Melba y Hernández, Roberto, "Políticas agrícolas en China y Japón, implicaciones para México", México y la Cuenca del Pacífico, vol. 49, núm. 7 / julio de 1999.

-Gorjón Gómez, Francisco, Arbitraje comercial y ejecución de laudos, McGraw-Hill, México, 2000.

Grupo de estudio en Jetro, Report on closer economic relations between Japan and Mexico (en formato PDF), Jetro de Japón; http://www.jetro.go.jp/ec/e/report/ fta_mexico/fta.pdf.

Grupo de estudio México-Japón sobre el fortalecimiento de las relaciones económicas bilaterales, Informe final (en formato PDF), Secretaría de Economía; http:// w w w. economia-snci.gob. $m x / s i c$ ph p/ Is23al. php?s $=516 \& p=1 \& \mid=1$.

Herrera Avendaño, Carlos, Fuentes de financiamiento, $2 a$ ed., Sicco, México, 2003.

Instituto de Relaciones Europeo-Latinoamericanas, EI acuerdo México-UE, pieza clave de una asociación integral, en la página Web de la SELA; http:// sela2.sela.org.

Instituto Matías Romero de Estudios Diplomáticos, La apertura de México al Pacífico, Secretaría de Relaciones Exteriores, México, 1990.

Jetro-México, Contribución para México de un fortalecimiento de las relaciones económicas entre México y Japón; en la página Web de Jetro México; http:// www.jetro.org.mx/aae_mexico_-_japon.htm (noviembre de 2003).

Kaibara, Yukio, Historia de Japón, Fondo de Cultura Económica, México, 2000.

Kawata, Tadashi, Usui, Mikoto y Ookuma, Tadauyki (compiladores), Desarrollo económico y la transferencia de tecnología - enfocando la industrialización de América Latina, Instituto nacional de investigación de los problemas internacionales (Nihon Kokusai Mondai Kenkyuzyo), Japón, 1983.

Kerber Palma, Víctor, Sushi con tortilla: relaciones entre México y Japón, 1995-2000, Foro internacional, XLI-4, octubre-diciembre de 2001.

Kidana, Shoichi, El avance del derecho de la propiedad intelectual en Asia - globalización de mercados después de la creación de wто/TRIPs y su influencia, Las reformas del derecho económico de los países en desarrollo y la globalización (compilado por Imaizumi, Shinya), Instituto de economías en desarrollo, Japón, 2005.

Lozoya, Jorge Alberto, Japón 1946-1990: el camino a la opulencia, Instituto Matías Romero de estudios diplomáticos, México, 1990.

Nishijima, Shouji, Se está moviendo el tratado de libre comercio entre México y Japón, World Affairs Weekly, 10 
de abril de 2002, JIJI press. Dicho artículo se puede leer en la página Web de la Universidad de Kobe; http:// www. rieb.kobe-u.ac.jp/ nisij ima/ wwindex2. html.

Okabe, Taku, "Posibilidad de negocios en Japón, a partir de las reformas del derecho mercantil", México y la Cuenca del Pacífico, Vol. 6, Núm. 19 / mayo-agosto de 2003, Departamento de Estudios del Pacífico de la Universidad de Guadalajara, México, 2003.

Pueda Peiro, Isabel, Las micro, pequeña y mediana empresas en México: importancia, entorno, asociación y subcontratación, Asociación y cooperación de las micro, pequeñas y medianas empresas, México, Chile, Argentina, Brasil, Italia y España, Porrúa, México, 1999.

Rodríguez Valencia, J oaquín, Administración de pequeñas y medianas empresas quinta ed., Thomson, Australia / Brasil / Canadá / España / Estados Unidos / Reino Unido / Singapur, 2002.

Secretaría de Economía, “¿Por qué es bueno un Acuerdo de Asociación Económica (AAE) con Japón?"; http:// w w w. economia-snci.gob.mx/sic_ph p / Is23al. php?s $=516 \& p=1 \& \mid=1$.

Secretaría de Economía, “Acuerdo de asociación económica entre México y Japón" en la dirección anterior.

Secretaría de Economía y la Comisión Intersecretarial de Política Industrial, Estadística de las Pymes; http:// www.cipi.gob.mx/Docs/Informaciondeprog/ PresentaCIPI.pdf; http://www.contactopyme.gob. $\mathrm{mx/}$ impactopymes. asp? Lenguaje $=0 \& C v e \_B=5$ (febrero de 2004).

Stallings, Barbara y Székely, Gabriel (compiladores), Japón, los Estados Unidos y la América Latina, Fondo de cultura económica, México, 1994.

Suárez Aguilar, Estela y Miguel Rivera Ríos, Pequeña empresa y modernización: análisis de dos dimensiones, UNAM, México, 1994.

Universidad Autónoma Metropolitana-Azcapotzalco División de Ciencias Sociales y Humanidades, Perspectivas de la empresa y la economía mexicana frente a la reestructuración productiva, UAM, México, 1995.

Uribarri Carpintero, Gonzalo, El arbitraje en México, Oxford, 1999.

Witker, Jorge, Régimen jurídico del comercio exterior, UNAM, México, 1991.

Varela Petito, Gonzalo, Sistemas de innovación: una comparación entre Japón y México, Foro internacional, XLII-1, enero-marzo de 2002.

\section{Noticias}

"A proteger carne de puerco de Japón", Periódico Akahata en Web, 24 de noviembre de 2003.

"Beneficia a agroindustria el acuerdo TLC con Japón: Evitan errores que se cometieron en tratados pasados", Mural en Web, 11 de marzo de 2004.

“Destaca Japón beneficios", Mural en Web, 11 de marzo 2004.

“Favorece a química el TLC con Japón: La negociación del TLC con Japón fue favorable para el sector químico del País", Mural en Web, 26 de marzo de 2004

"Firman hoy Fox y Koizumi el acuerdo comercial, liberación total, en 20 años", El Universal en Web, 17 de septiembre de 2004.

“J apón y México sellarán amistad estratégica con tratado comercio", EFE en Web, 10 de septiembre de 2004.

“Llama IP a aprovechar el TLC con Japón: Las áreas de negocio son agrícola, textil y calzado: CEESP", El Universal en Web, 5 de abril de 2004.

“México y Japón firmaron el acuerdo de asociación económica", Es más (servidor de internet), 17 de septiembre de 2004; http://www.esmas.com/ noticierostelevisa/mexico/392154.html.

“Se excluirá la carne de puerco de México, reconsideración de aranceles emergentes por razón del tratado de libre comercio", Noticia Kyodo en Web, 17 de septiembre de 2004.

“Se firmó el tratado de libre comercio, el primer acuerdo inclusivo, se entrará en vigor desde abril del próximo año", Periódico Sankei en Web, 18 de septiembre de 2004.

“Ven inicio del TLC México-J apón en el 2005: La SE estima que la inversión japonesa a México crecerá a un ritmo anual de mil 300 millones de dólares, y que se generarán 270 mil empleos en....", Mural en Web, 11 de marzo de 2004.

\section{O tras fuentes}

Bancomext; www.bancomext. $\mathrm{mx}$ Nafín; http://www.nafin.com/portalnf/ m: 